\title{
Clinical and Radiologic Results Comparing the Periarticular Proximal Humerus Locking Plate and Polarus Nail for Displaced Proximal Humerus Fractures
}

\author{
Young-Kyoung Min, Seung-Jun Lee ${ }^{1 \bowtie}$, Heui-Chul Gwak, Sang-Woo Kang ${ }^{1}$, Kuen-Tak Suh ${ }^{1}$ \\ Department of Orthopedic Surgery, Inje University Busan Paik Hospital, Inje University College of Medicine, ${ }^{1}$ Department of Orthopaedic Surgery, Pusan National \\ University Yangsan Hospital, Pusan National University School of Medicine, Busan, Korea
}

\begin{abstract}
Background: This study compared the clinical and radiological outcomes of the single calcar screw plate and Polarus nail techniques for the treatment of the proximal humerus fractures.

Methods: Seventy-two patients diagnosed with displaced proximal humerus fracture were enrolled for the study. Of these, 50 patients underwent the locking plate surgery with a single calcar screw (plate group), whereas 22 patients underwent the Polarus nail surgery (nail group). The plate group was further divided into plate 1 group (with medial support), and plate 2 group (without medial support). The radiological and functional results of both groups were compared to the nail group.

Results: The $\alpha$ angle 1 year after surgery was significantly different between plate 1 and plate 2 , and plate 2 and nail groups ( $p=0.041$, $p=0.043$, respectively). The ratio that does not satisfy the reference value of $\gamma$ angle was $2.8 \%$ in plate $1,7.1 \%$ in plate 2 and $22.7 \%$ in nail group $(p=0.007)$; there was a significant difference between plate 1 and nail group, and plate 2 and nail group $(p=0.014, p=0.033$, respectively).

Conclusions: No significant differences were observed in the clinical results between locking plate and Polarus nail. However, in the plate 2 group and nail group, the rate of failure to maintain reduction during the 1-year period after surgery was statistically and significantly higher than the plate 1 group (level of evidence: level IV, case series, treatment study).
\end{abstract}

(Clin Shoulder Elbow 2017;20(4):208-216)

Key Words: Humeral fractures; Proximal; Locking plate; Intramedullary nail

\section{Introduction}

Proximal humeral fractures account for approximately 5\% of total fractures, and are common amongst geriatrics due to increase in the mean age and the prevalence of osteoporosis. ${ }^{1,2)}$ Reports indicate that about $20 \%$ of proximal humeral fractures require surgical treatment, and most of the cases undergoing surgery are 3- and 4-part fractures. ${ }^{3,4)}$ The goal of surgery is to provide enough fixation at the correct anatomical location, with minimal soft tissue damage, so that early rehabilitation of the shoulder joint is possible. Several surgical methods introduced for this purpose include the K-wire fixation and tension band technique, metal plate and screw fixation, intramedullary fixation, and arthroplasty. ${ }^{5}$ The advantages and disadvantages of each treatment method differ, and various outcomes are reported for each treatment. In particular, compared to a conventional metal plate, a locking metal plate preserves the blood supply at the fracture site and has the advantage of achieving angular stability and rotational stability at the initial stage. ${ }^{6,7)}$ Also, the development of anatomically precontoured-locking plates

Received June 23, 2017. Revised August 14, 2017. Accepted August 23, 2017.

Correspondence to: Seung-Jun Lee

Department of Orthopaedic Surgery, Pusan National University Yangsan Hospital, Pusan National University School of Medicine, 20 Geumo-ro, Mulgeum-up, Yangsan 50612, Korea

Tel: +82-55-360-2125, Fax: +82-55-360-2155, E-mail: ninanojune@naver.com

IRB approval (No. 05-2017-078).

Financial support: None. Conflict of interests: None. 
have reported satisfactory surgical outcomes, and are therefore being used worldwide. ${ }^{8,9)}$ Intramedullary nailing is another commonly used surgical method. Its advantages include a reduced risk of bleeding due to a minimal skin incision, a relatively lower possibility of avascular necrosis (AVN), higher varus and valgus rotation resistance, and faster functional recovery of the shoulder joint after surgery. ${ }^{10-14)}$ Intramedullary fixation has the disadvantage that fixation strength of the humerus and bone fixation is relatively weak. However, the proximal humeral nail, especially the non-locking Polarus nail (Acumed, Beaverton, OR, USA), is capable of inserting cancellous screws in various directions in the humeral head. ${ }^{10,11)}$

Having their own advantages and disadvantages, these two techniques are the treatment options that surgeons resort to for proximal humeral fractures. Several comparative studies have been reported. ${ }^{15-19)}$ However, in the proximal humerus fracture, comparative studies of internal fixation were performed for periarticular proximal humerus locking plate with a single calcar screw (Zimmer, Warsaw, IN, USA), whereas studies on Polarus intramedullary nail are rare. Considering proximal humerus fractures in patients with osteoporosis, there is additional concern regarding the degree of reduction maintenance or rotational stability due to poor bone quality. We hypothesized that the clinical and radiological outcomes between single calcar screw plate and non-locking Polarus nail would be different, because non-locking nails might have a disadvantage for rotational stability, and single calcar screw plate might have a disadvantage for calcar stability. This study therefore undertook to compare the clinical and radiological results of single calcar screw plate and non-locking Polarus intramedullary nail surgeries, and to confirm whether the postoperative radiologic results are sustained.

\section{Methods}

\section{Subjects of Study}

This study was conducted after receiving approval of the Institutional Review Board of Pusan National University Yangsan Hospital (IRB No. 05-2017-078). Formal consent is not required for the study. From March 2011 to January 2016, 98 patients diagnosed with displaced proximal humerus fracture were enrolled at a single institute. The fracture were classified according to the Neer classification system. ${ }^{4)}$ Inclusion criteria were patients who had proximal humeral fractures with a displacement of more than $1 \mathrm{~cm}$ or angulation more than $45^{\circ}$ in the shoulder $x-$ ray (true anteroposterior [AP] view and outlet-view), and whose surgical intervention was either a periarticular proximal humerus locking plate or a Polarus nail for internal fixation. The exclusion criteria were as follows: cases of conservative treatment, pediatric patients under 15 years, isolated fracture of the greater tuberosity, fracture with nerve injury, previous shoulder surgery on the same side, arthroplasty, open fracture, or pathological fracture.
Clinical and radiological results were retrospectively analyzed in 72 patients having the above criteria. All patients underwent surgery by a single surgeon. Periarticular proximal humerus locking plate surgery was performed for 50 patients; 14 males and 36 females, mean age $63.8 \pm 15.8$ years. Of these, 27 patients $(54.0 \%)$ were over 65 years, and the mean T score in bone mineral density (BMD) was -2.11 . The mean time to surgery after trauma was $3.2 \pm 1.1$ days, and the average follow-up period was $19.8 \pm 8.1$ months. The causes of injury were slipping $(25$ cases), traffic accident (12 cases), and falls (13 cases). According to the Neer fracture classification, there were 19 patients in group II, 30 patients in group III, and 1 patient in group IV. Polarus nail surgery was performed for 22 patients; 8 males and 14 females, mean age $58.1 \pm 17.8$ years. Of these, 11 patients $(50.0 \%)$ were over 65 years, and the mean BMD was -1.98 . The mean time to surgery after trauma was $2.8 \pm 1.2$ days, and the average follow-up period was $21.1 \pm 7.4$ months. The causes of injury were slipping (11 cases), traffic accident (5 cases), and falls (6 cases). According to the Neer fracture classification, there were 7 patients in group II, 13 patients in group III, and 2 patients in group IV (Table 1).

\section{Surgical Method}

The surgical method was decided according to the year of enrollment: 2011, 2014, and 2015: plate; 2012 and 2013: nail. The periarticular proximal humerus locking plate surgery was

Table 1. Demographic Characteristics

\begin{tabular}{|c|c|c|c|}
\hline Variable & Plate group & Nail group & $p$-value ${ }^{*}$ \\
\hline No. of patient & 50 & 22 & \\
\hline Sex & & & 0.478 \\
\hline Male & 14 & 8 & \\
\hline Female & 36 & 14 & \\
\hline Age (yr) & $63.8 \pm 15.8$ & $58.1 \pm 17.8$ & 0.281 \\
\hline Age over 65 years & $27(54.0)$ & $11(50.0)$ & 0.412 \\
\hline Fracture type $^{\dagger}$ & & & 0.367 \\
\hline II & 19 & 7 & \\
\hline III & 30 & 13 & \\
\hline IV & 1 & 2 & \\
\hline Interval between surgery and injury (d) & $3.2 \pm 1.1$ & $2.8 \pm 1.2$ & 0.758 \\
\hline Follow-up period (mo) & $19.8 \pm 8.1$ & $21.1 \pm 7.4$ & 0.645 \\
\hline Trauma history & & & 0.990 \\
\hline Slip down & 25 & 11 & \\
\hline Traffic accident & 12 & 5 & \\
\hline Fall down & 13 & 6 & \\
\hline
\end{tabular}

Values are presented as number only, mean \pm standard deviation or number (\%). ${ }^{*}$ Student's t-test or chi-square test. ${ }^{\dagger}$ Graded according to the criteria by Neer. ${ }^{4)}$ 
performed under general anesthesia. Briefly, the patient was positioned in a beach chair placed on a radiopaque operating table, after which a skin incision of about $10 \mathrm{~cm}$ was made using a delto-pectoral approach. The fracture site was exposed while paying attention to the anterior circumflex humeral artery and the axillary nerve around the biceps tendon. For insufficient field of view, the proximal portion of the pectoralis major portion was released about $1-1.5 \mathrm{~cm}$ for improved viewing. A nonabsorbable suture (Ethibond; Ethicon, Somerville, NJ, USA) was then sutured over the supraspinatus, infraspinatus and subscapularis muscles. Under the $\mathrm{C}$-arm image enhancer, open reduction of the fracture site was performed by traction of the suture and upper arm, considering the displacement and angulation of the fracture site by supraspinatus and subscapularis, pectoralis major, and biceps brachii muscles. After satisfactory reduction, a temporary fixation was performed using a K-wire, and fixed with a periarticular proximal humerus locking plate. Additional fixation was secured by fastening the supraspinatus and subscapularis muscles, and the infraspinatus tendon to the small holes in the proximal portion of the plate, using non-absorbable sutures. Thereafter, the shoulder motion was performed under the Carm image enhancer to check the fixation of the fracture was well maintained, the penetration of the screw into the joint, and the impingement between the metal plate and the acromion. In our surgeries, the isolated calcar screw of the periarticular proximal humerus locking plate was planned to support the medial cortex.

The Polarus nail surgery was also performed in the same position under general anesthesia. A skin incision of approximately $4 \mathrm{~cm}$ was made, following which the humeral head was approached via the deltoid split approach. For the nail insertion, a longitudinal incision of minimal length was made in the proximal portion of the supraspinatus attachment, and tagged with a 5-0 non-absorbable suture (Ethibond; Ethicon). The reduction of the fracture was performed by traction and abduction, adduction, and rotation, using the C-arm image enhancer. The entry portal was punctured using a cannulated drill bit on the immediate medial side of the greater tuberosity, $1 \mathrm{~cm}$ behind the long head of biceps tendon. The nail was inserted into the proximal portion of the humeral head, and into the distal portion of the fracture site, while maintaining the fracture under the C-arm image enhancer. The proximal portion of the Polarus nail was implanted under the surface of the humeral head to prevent subacromial impingement. After the nail was fully implanted, three fixed $5 \mathrm{~mm}$ locked cancellous screws were inserted into the humeral head for proximal locking, following which 1 or 2 distal cortical screws were inserted. A 5-0 non-absorbable suture was used to tag the infraspinatus and post supraspinatus on the posterior side, and the subscapularis of the lesser tuberosity on the anterior side; a tension band suturing was performed by tying each tagged suture. Thereafter, the incisional supraspinatus was sutured using a 5-0 non-absorbable suture tagging with supraspinatus. Postoperatively, an abduction brace was used for fixation, and 2 days after surgery, passive forward elevation exercise was performed in the supine position. From 4 to 6 weeks after surgery, active assisted exercise, including external rotation and internal rotation, was performed. From 8 weeks after surgery, active joint exercise and daily life were resumed, and work or muscle strengthening exercise was started at 3 months after the surgery.

\section{Clinical and Radiological Evaluation}

All patients were assessed by a single surgeon for range of motion (ROM), American Shoulder and Elbow Surgeons (ASES) scores, Constant Scoring System (CSS) score, and visual analogue scale (VAS); assessment was preoperative and postoperative at 1, 3, 6, and 12 months follow-up. Active ROM measurement included 4 movements: forward flexion and abduction in the scapular plane, external rotation with the arm at the side, and internal rotation. Internal rotation was estimated by determining how far the patient could reach their thumb along the spinal segments. For the purpose of statistical analysis, the spinal segment was converted into numbers: segment at $\mathrm{T} 1$ through $\mathrm{T} 12$ were designated as 1 through 12, segments at L1 through L5 were designated as 13 through 17 , and the sacrum was designated as 18. The x-rays were taken preoperatively, immediately after surgery, and at 2 weeks, 1, 2, 3, 6, and 12 months postoperatively. Radiologic results were measured by two orthopedic surgeons; in case of differences, the average value was used. Postoperative $\mathrm{x}$-rays were analyzed according to the Gardner et al. ${ }^{20)}$ criteria: the presence of the medial support was confirmed when 1) the anatomical reduction without the medial cortex of the proximal

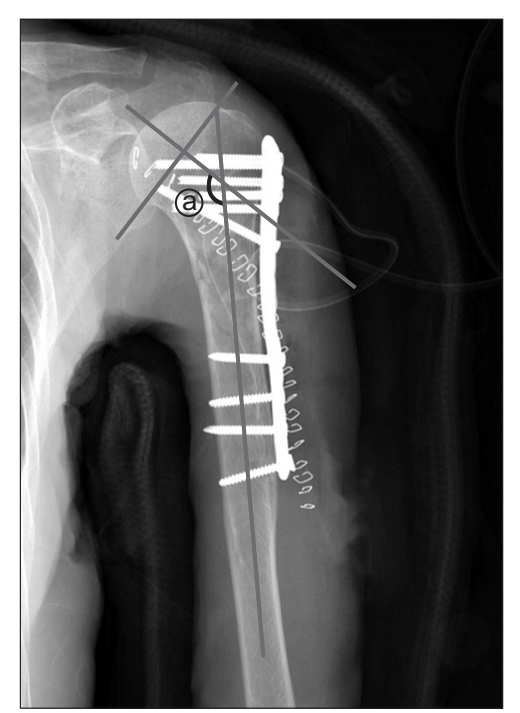

Fig. 1. Neck-shaft angle (a): angle between the line perpendicular to the anatomical neck and the centerline of the diaphysis. 
fragment was not comminuted, 2) the humeral shaft was inserted into the humeral head, and 3) the medial screw was located within $5 \mathrm{~mm}$ of the inferomedial subchondral bone under the humeral head. Observation of the bridging callus on subsequent $\mathrm{x}$-rays confirmed formation of the bony union after surgery. On the AP x-ray taken immediately after surgery and at 1 year postoperatively, the angle between the perpendicular to the anatomical neck and the centerline of the diaphysis (neck-shaft angle, NSA) was measured and evaluated using the Paavolainen et al. ${ }^{21)}$ methods (Fig. 1). We measured the $\alpha$ angle (as an angle of the varus-valgus angle) on the $x$-ray AP view, and the $\gamma$ angle (as an anteversion-retroversion angle) on the $Y$ view (Fig. 2). The appropriateness of the reduction was evaluated by referring to literature results $\left(\alpha=45^{\circ} \pm 15^{\circ}, \gamma=60^{\circ} \pm 15^{\circ}\right)$. $^{22,23)}$ In addition, we measured the degree of displacement in the greater tuberosity, and a displacement of $5 \mathrm{~mm}$ or more was considered to be significant. ${ }^{24)}$ Also, the humeral head necrosis, screw protrusion, and hardware failure were evaluated on the x-ray. During the follow-up period, complications, such as infection, subacromial impingement and rotator cuff tear were observed. At 6 months after surgery, all patients underwent ultrasonography to confirm the presence of rotator cuff tear.

Statistical analysis was performed using the IBM SPSS ver. 22.0 (IBM Co., Armonk, NY, USA). Student's t-test was used for continuous variables, and Mann-Whitney U-test for non-normal distributions. Categorical variables were tested by the chi-square test or Fisher exact test. One-way ANOVA test was performed for comparison of subgroups. If there was a significant difference in the one-way ANOVA test, the Bonferroni method was used for the post hoc test. The significance threshold was set at 0.05 .

\section{Results}

\section{Clinical Results}

Twelve months after surgery, the ASES score was $71.5 \pm 6.1$ in the plate group and $69.2 \pm 7.1$ in the nail group $(p=0.158)$, CSS was $76.7 \pm 6.1$ in the plate group and $74.7 \pm 8.6$ in the nail group ( $p=0.265)$, and VAS was $1.5 \pm 1.0$ in the plate group and $1.5 \pm 1.1$ in the nail group $(p=0.985)$. All clinical outcomes improved after surgery, but there was no significant difference between the two groups. At 12 months after surgery, the mean ROM of the plate and nail groups were measured. Forward flexion was $131.5^{\circ} \pm 12.1^{\circ}$ and $138.9^{\circ} \pm 10.8^{\circ}(p=0.447)$, abduction was $120.5^{\circ} \pm 9.8^{\circ}$ and $125.2^{\circ} \pm 10.3^{\circ}(p=0.395)$, external rotation was $47.6^{\circ} \pm 5.1^{\circ}$ and $48.5^{\circ} \pm 4.6^{\circ}(p=0.337)$, and internal rotation was in T10 $\pm 1.4(10.4 \pm 1.4)$ and T10 \pm 1.1 $(10.2 \pm 1.1)(p=0.695)$, respectively (Table 2$)$.

\section{Radiological Results}

Bone union was confirmed in all patients after the operation. Mean bone union time was $12.9 \pm 2.1$ weeks in the plate group and $13.9 \pm 2.6$ weeks in the nail group $(p=0.142)$. Immediately after surgery, NSA was $136.3^{\circ} \pm 8.5^{\circ}$ in the plate group and $140.3^{\circ} \pm 7.2^{\circ}$ in the nail group $(p=0.159)$. One year after surgery, NSA was $134.2^{\circ} \pm 7.4^{\circ}$ in the plate group and $138.0^{\circ} \pm 5.7^{\circ}$ in the nail group $(p=0.221)$. The difference between the groups immediately after the operation and after 1 year was $2.1^{\circ} \pm 2.7^{\circ}$ in the plate group and $2.3^{\circ} \pm 4.6^{\circ}$ in the nail group $(p=0.489)$.

The $\alpha$ angle immediately after the surgery was $47.3^{\circ} \pm 7.0^{\circ}$ in the plate group and $48.4^{\circ} \pm 7.5^{\circ}$ in the nail group $(p=0.547)$. The $\gamma$ angle was $60.3^{\circ} \pm 7.3^{\circ}$ in the plate group and $58.7^{\circ} \pm$ $8.5^{\circ}$ in the nail group $(p=0.426)$. The ratio that does not satisfy the reference value of $\alpha$ angle was $22.0 \%$ in the plate group and $31.8 \%$ in the nail group $(p=0.390)$. The ratio that does not sat-
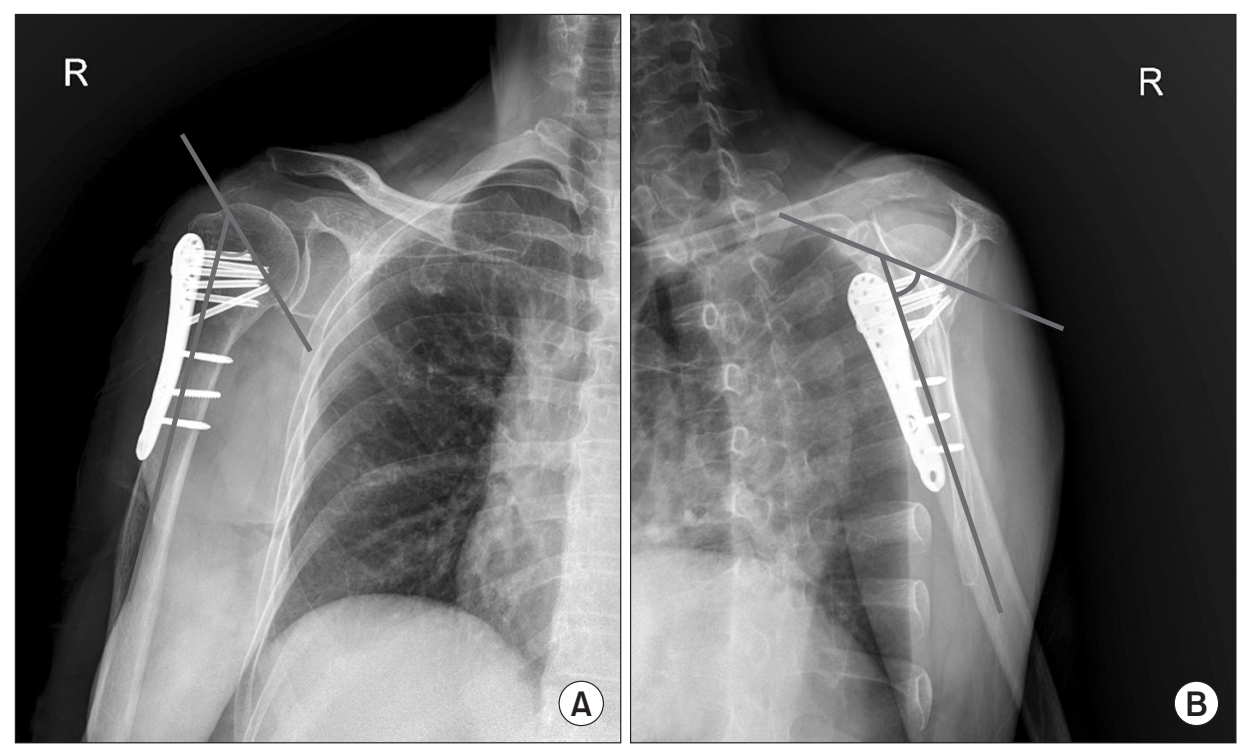

Fig. 2. (A) $\alpha$ angle: angle created at the intersection of a line through the anatomic neck and a line parallel to the proximal humeral shaft. (B) $\gamma$ angle: angle between a line through the anatomic neck and a line parallel to the proximal humeral shaft. 
Table 2. Clinical Comparisons of Plate Group and Nail Group at Last Followup Period

\begin{tabular}{|c|c|c|c|}
\hline Variable & Plate group & Nail group & $p$-value ${ }^{*}$ \\
\hline ASES score & $71.5 \pm 6.1$ & $69.2 \pm 7.1$ & 0.158 \\
\hline CSS & $76.7 \pm 6.1$ & $74.7 \pm 8.6$ & 0.265 \\
\hline VAS & $1.5 \pm 1.0$ & $1.5 \pm 1.1$ & 0.985 \\
\hline \multicolumn{4}{|l|}{$\operatorname{ROM}\left({ }^{\circ}\right)$} \\
\hline Forward elevation & $131.5 \pm 12.1$ & $138.9 \pm 10.8$ & 0.447 \\
\hline Abduction & $120.5 \pm 9.8$ & $125.2 \pm 10.3$ & 0.395 \\
\hline External rotation & $47.6 \pm 5.1$ & $48.5 \pm 4.6$ & 0.337 \\
\hline Internal rotation $^{\dagger}$ & $\begin{array}{c}\mathrm{T} 10 \pm 1.4 \\
(10.4 \pm 1.4)\end{array}$ & $\begin{array}{c}\mathrm{T} 10 \pm 1.1 \\
(10.2 \pm 1.1)\end{array}$ & 0.695 \\
\hline
\end{tabular}

Values are presented as mean \pm standard deviation.

ASES: American Shoulder and Elbow Surgeons, CSS: Constant Scoring System, VAS: visual analogue scale, ROM: range of motion.

${ }^{*}$ Student's t-test or Mann-Whitney U-test. ${ }^{\dagger}$ The internal rotation was estimated by determining how far the patient could reach their thumb along the spinal segments. For the purpose of statistical analysis, the spinal segment was converted into numbers: segment at T1 through T12 were designated as 1 through 12, segments at L1 through L5 were designated as 13 through 17, and the sacrum was designated as 18

isfy the reference value of $\gamma$ angle was $4.0 \%$ in plate group and $13.6 \%$ in nail group $(p=0.163)$.

The $\alpha$ angle 1 year after surgery was $44.1^{\circ} \pm 6.8^{\circ}$ in the plate group and $45.8^{\circ} \pm 7.0^{\circ}$ in the nail group $(p=0.311)$. The $\gamma$ angle 1 year after the surgery was $60.5^{\circ} \pm 6.8^{\circ}$ in the plate group and $56.3^{\circ} \pm 7.1^{\circ}$ in the nail group $(p=0.132)$. The ratio that does not satisfy the reference value of $\alpha$ angle was $26.0 \%$ in the plate group and $36.3 \%$ in the nail group $(p=0.373)$. The ratio that does not satisfy the reference value of $\gamma$ angle was $4.0 \%$ in the plate group and $22.7 \%$ in the nail group $(p=0.013)$.

Gap of the $\alpha$ angle immediately after surgery and after 1 year of surgery was $-3.2 \pm 6.4$ in plate group and $-2.6 \pm 3.1$ in nail group $(p=0.237)$. Gap of the $\gamma$ angle immediately after surgery and after 1 year of surgery was $0.2^{\circ} \pm 2.8^{\circ}$ in plate group and $-2.4^{\circ} \pm 3.1^{\circ}$ in nail group $(p=0.014)$. Comparing results of the gap of $\gamma$ angle immediately after surgery and after 1 year of surgery, we observed that the nail group had a significantly greater difference than the plate group (Table 3).

\section{Subgroup Analysis}

In the plate group, postoperative $x$-rays revealed the presence of medial support in 36 patients $(72.0 \%)$; the two subgroups (plate 1 group: with medial support group; plate 2 group: without medial support group) were compared the nail group. ASES score and VAS was not significantly different in the three groups ( $p=0.207, p=0.795$, respectively), but CSS was significantly higher in the plate 1 group than in the plate 2 group, as compared to the nail group $(p=0.032)$. Twelve months after sur-
Table 3. Radiological Results of Plate Group and Nail Group: Immediately after Surgery Period and Postoperative Period (POP)

\begin{tabular}{lccc}
\hline \multicolumn{1}{c}{ Variable } & Plate group & Nail group & $p$-value \\
\hline Bone union $(\mathrm{wk})$ & $12.9 \pm 2.1$ & $13.9 \pm 2.6$ & 0.142 \\
\hline NSA $\left(^{\circ}\right)$ & & & \\
\hline After surgery & $136.3 \pm 8.5$ & $140.3 \pm 7.2$ & 0.159 \\
\hline POP 1 year & $134.2 \pm 7.4$ & $138.0 \pm 5.7$ & 0.221 \\
\hline Gap & $2.1 \pm 2.7$ & $2.3 \pm 4.6$ & 0.489 \\
\hline$\alpha$ angle & & & \\
\hline After surgery $\left(^{\circ}\right)$ & $47.3 \pm 7.0$ & $48.4 \pm 7.5$ & 0.547 \\
\hline Unsatisfactory ratio & 22.0 & 31.8 & 0.390 \\
\hline$\gamma$ angle & & & \\
\hline After surgery $\left(^{\circ}\right)$ & $60.3 \pm 7.3$ & $58.7 \pm 8.5$ & 0.426 \\
\hline Unsatisfactory ratio & 4.0 & 13.6 & 0.163 \\
\hline$\alpha$ angle & & & \\
\hline POP 1 year $\left(^{\circ}\right)$ & $44.1 \pm 6.8$ & $45.8 \pm 7.0$ & 0.311 \\
\hline Unsatisfactory ratio & 26.0 & 36.3 & 0.373 \\
\hline$\gamma$ angle & & & \\
\hline POP 1 year $\left(^{\circ}\right)$ & $60.5 \pm 6.8$ & $56.3 \pm 7.1$ & 0.132 \\
\hline Unsatisfactory ratio & 4.0 & 22.7 & 0.013 \\
\hline$\alpha$ angle: gap $\left(^{\circ}\right)$ & $-3.2 \pm 6.4$ & $-2.6 \pm 3.1$ & 0.237 \\
\hline angle: gap $\left(^{\circ}\right)$ & $0.2 \pm 2.8$ & $-2.4 \pm 3.1$ & 0.014 \\
\hline
\end{tabular}

Values are presented as mean \pm standard deviation or percent only.

NSA: neck-shaft angle.

${ }^{*}$ Student's t-test or Mann-Whitney U-test.

gery, the mean ROM was not significantly different in the three groups. Mean bone union time was $11.9 \pm 1.9$ weeks in plate 1 group, $18.0 \pm 2.1$ weeks in plate 2 group, and $13.9 \pm 2.6$ weeks in nail group; the plate 1 group had a significantly shorter time than plate 2 group $(p=0.038)$. Immediately after surgery, NSA was not significantly different in the three groups $(p=0.435)$. However, 1 year after surgery, the NSA showed a significant difference between plate 2 and nail group $(p=0.029)$. The difference in the NSA immediately after the operation and 1 year later was significantly different between subgroups plate 1 and plate $2(p=0.023)$.

There was no significant difference in the $\alpha$ angle and $\gamma$ angle of the three groups immediately after surgery $(p=0.459$, $p=0.328$, respectively). The ratio that does not satisfy the reference value of $\alpha$ angle was $13.9 \%$ in plate $1,42.9 \%$ in plate 2 , and $31.8 \%$ in nail group; there was a significant difference between plate 1 and plate 2 , and plate 1 and nail group $(p=0.013$, $p=0.034$, respectively). The ratio that does not satisfy the reference value of $\gamma$ angle was $2.8 \%$ in plate $1,7.1 \%$ in plate 2 and $13.6 \%$ in nail group; the difference between plate 1 and nail group was significant $(p=0.028)$. 
The $\alpha$ angle at 1 year after surgery showed a significant difference between plate 1 and plate 2, and plate 2 and nail group $(p=0.041, p=0.043$, respectively). However, the $\gamma$ angle was not significantly different in the three groups $(p=0.347)$. The ratio that does not satisfy the reference value of $\alpha$ angle was $25.0 \%$ in plate $1,28.5 \%$ in plate 2 , and $36.3 \%$ in the nail group $(p=0.593)$. The ratio that does not satisfy the reference value of $\gamma$ angle was $2.8 \%$ in plate $1,7.1 \%$ in plate 2 , and $22.7 \%$ in nail group ( $p=0.007$ ); the difference between plate 1 and plate nail group, and plate 2 and nail group was significant $(p=0.014$, $p=0.033$, respectively) (Table 4$)$

\section{Complications}

During the follow-up period, there were no infections in the plate and nail groups. As presented in Table 5, there were no significant difference in severe and minor complications in plate group and nail groups. The rate of reoperation between the plate group and the nail group was also similar $(p=0.457)$. The reasons for reoperation in the plate group were loss of reduction of humeral head, AVN, and hardware failure (1 case each); com-

Table 4. Clinical and Radiological Results of Plate 1 Group, Plate 2 Group and Nail Group: Immediately after Surgery and Postoperative Period

\begin{tabular}{|c|c|c|c|c|c|}
\hline Variable & Plate 1 group & Plate 2 group & Nail group & $p$-value ${ }^{*}$ & $p$-value ${ }^{\dagger}$ \\
\hline ASES score & $71.8 \pm 5.2$ & $70.1 \pm 5.9$ & $69.2 \pm 7.1$ & 0.207 & \\
\hline CSS & $78.1 \pm 4.7$ & $73.9 \pm 5.1$ & $74.7 \pm 8.6$ & 0.034 & Plate 1-plate 2: 0.032 \\
\hline VAS & $1.5 \pm 1.2$ & $1.6 \pm 0.7$ & $1.5 \pm 1.1$ & 0.795 & \\
\hline \multicolumn{6}{|l|}{$\mathrm{ROM}\left({ }^{\circ}\right)$} \\
\hline Forward elevation & $132.1 \pm 11.3$ & $130.3 \pm 10.9$ & $138.9 \pm 10.8$ & 0.635 & \\
\hline Abduction & $122.4 \pm 9.5$ & $116.6 \pm 9.7$ & $125.2 \pm 10.3$ & 0.197 & \\
\hline External rotation & $47.9 \pm 4.8$ & $47.0 \pm 5.0$ & $48.5 \pm 4.6$ & 0.584 & \\
\hline Internal rotation $^{*}$ & $\begin{array}{c}\mathrm{T} 10 \pm 1.3 \\
(10.2 \pm 1.3)\end{array}$ & $\begin{array}{c}\mathrm{T} 10 \pm 1.4 \\
(10.6 \pm 1.4)\end{array}$ & $\begin{array}{c}\mathrm{T} 10 \pm 1.1 \\
(10.2 \pm 1.1)\end{array}$ & 0.695 & \\
\hline Bone union (wk) & $11.9 \pm 1.9$ & $18.0 \pm 2.1$ & $13.9 \pm 2.6$ & 0.025 & Plate 1-plate 2: 0.038 \\
\hline NSA $\left(^{\circ}\right)$ & $136.5 \pm 8.1$ & $135.9 \pm 8.4$ & $140.3 \pm 7.3$ & 0.435 & \\
\hline After surgery & $136.5 \pm 8.1$ & $135.9 \pm 8.4$ & $140.3 \pm 7.3$ & 0.435 & \\
\hline POP 1 year & $136.2 \pm 7.1$ & $130.2 \pm 6.9$ & $138.0 \pm 5.7$ & 0.027 & Plate 2-nail: 0.029 \\
\hline Gap & $0.3 \pm 1.8$ & $5.7 \pm 3.8$ & $2.3 \pm 4.6$ & 0.017 & Plate 1-plate 2: 0.023 \\
\hline$\alpha$ angle & $47.6 \pm 7.0$ & $46.7 \pm 6.7$ & $48.4 \pm 7.5$ & 0.459 & \\
\hline After surgery $\left(^{\circ}\right)$ & $47.6 \pm 7.0$ & $46.7 \pm 6.7$ & $48.4 \pm 7.5$ & 0.459 & \\
\hline Unsatisfactory ratio & 13.9 & 42.9 & 31.8 & 0.024 & $\begin{array}{l}\text { Plate 1-plate 2: } 0.013 \\
\text { Plate 1-nail: } 0.034\end{array}$ \\
\hline \multicolumn{6}{|l|}{$\gamma$ angle } \\
\hline After surgery $\left(^{\circ}\right)$ & $60.7 \pm 7.3$ & $59.5 \pm 7.1$ & $58.7 \pm 8.5$ & 0.328 & \\
\hline Unsatisfactory ratio & 2.8 & 7.1 & 13.6 & 0.017 & Plate 1-nail: 0.028 \\
\hline \\
\hline POP 1 year $\left(^{\circ}\right)$ & $45.9 \pm 6.5$ & $40.3 \pm 6.9$ & $45.8 \pm 7.0$ & 0.036 & $\begin{array}{l}\text { Plate 1-plate 2: } 0.041 \\
\text { Plate 2-nail: } 0.043\end{array}$ \\
\hline Unsatisfactory ratio & 25.0 & 28.5 & 36.3 & 0.593 & \\
\hline$\gamma$ angle & $60.7 \pm 6.8$ & $60.1 \pm 5.9$ & $56.3 \pm 7.1$ & 0.347 & \\
\hline POP 1 year $\left(^{\circ}\right)$ & $60.7 \pm 6.8$ & $60.1 \pm 5.9$ & $56.3 \pm 7.1$ & 0.347 & \\
\hline Unsatisfactory ratio & 2.8 & 7.1 & 22.7 & 0.007 & $\begin{array}{l}\text { Plate 1-nail: } 0.014 \\
\text { Plate 2-nail: } 0.033\end{array}$ \\
\hline
\end{tabular}

Values are presented as mean \pm standard deviation or percent only.

ASES: American Shoulder and Elbow Surgeons, CSS: Constant Scoring System, VAS: visual analogue scale, ROM: range of motion, NSA: neck-shaft angle, POP: postoperative period.

${ }^{*}$ One-way ANOVA test. ${ }^{\dagger}$ Bonferroni test (post hoc test). ${ }^{*}$ The internal rotation was estimated by determining how far the patients could reach their thumb along the spinal segments. For the purpose of statistical analysis, the spinal segment was converted into numbers: segment at T1 through T12 were designated as 1 through 12, segments at L1 through L5 were designated as 13 through 17, and the sacrum was designated as 18. 
Table 5. Complication of Plate Group and Nail Group

\begin{tabular}{lccc}
\hline \multicolumn{1}{c}{ Variable } & Plate group & Nail group & $p$-value \\
\hline Infection & 0.0 & 0.0 & \\
Subacromial impingement & 4.0 & 0.0 & 0.341 \\
Rotator cuff tear & 4.0 & 13.6 & 0.138 \\
GT displaced & 6.0 & 13.6 & 0.280 \\
Loss of reduction of humeral head & 4.0 & 9.1 & 0.385 \\
Humeral head AVN & 4.0 & 4.5 & 0.915 \\
\hline Screw protrusion & 2.0 & 4.5 & 0.545 \\
\hline Hardware failure & 4.0 & 9.1 & 0.385 \\
\hline Reoperation & 6.0 & 13.6 & 0.457 \\
Total number of complications & $13(26.0)$ & $9(40.9)$ & 0.059 \\
\hline Number of patients with complications & $8(16.0)$ & $9(40.9)$ & 0.022 \\
\hline
\end{tabular}

Values are presented as percent only or number (\%).

GT: greater tuberosity, AVN: avascular necrosis.

*The chi-square test or Fisher exact test.

plications in the nail group included loss of reduction of humeral head ( 2 cases) and hardware failure ( 1 case). However, the total number of patients with complications was 8 patients $(16.0 \%)$ in the plate group and 9 patients (40.9\%) in the nail group, with nail group showing significantly higher rate $(p=0.022)$.

\section{Discussion}

In proximal humerus fractures, several papers have reported good results after surgery using the plate method ${ }^{6,7,9,25)}$ or the nail method. ${ }^{11-14,26)}$ The average CSS score of these papers is about 70-80 points. In our study, our results were similar results for both the plate group $(76.7 \pm 6.1)$ and nail group $(74.7 \pm$ 8.6). The ASES score, VAS, and ROM were also similar in both groups, and the clinical outcomes were also similar. Radiology confirmed that there was no significant difference in the union time, as well as the NSA and $\alpha$ angle between the two groups. However, the $\gamma$ angle, which indicates the extent of anteversion and retroversion of the humerus, showed statistically significant difference between the two groups. Increase of the unsatisfactory ratio of nail group after 1 year indicates that this group is unable to maintain the reduction state after surgery. This is in contrast to the result that intramedullary nail fixation, which has been confirmed in previous references, has a biomechanically lesser lever arm effect on the bending force; Hessmann et al. ${ }^{27}$ have also reported intramedullary nail fixation to be biomechanically more strong for the treatment of unstable proximal humerus fractures, than locked or T-shaped plates. This is in contrast to the results of Kitson et al. ${ }^{12)}$ who reported that nail fixation was significantly stronger in cantilever bending with respect to valgus and flexion, extension, and torsion; also, Mølster et al. ${ }^{13)}$ reported that Polarus nail is the most torsionally resistant and has less angular displacement. We hypothesis that our contradicting results of the $\gamma$ angle might have resulted from the following factors: 1) it increased from 3 patients to 5 patients when evaluated as a number rather than as a ratio, and we considered that this increase in ratio of 2 patients in the relatively small number of the total nail group, was statistically reflected. If the total number of cases were increased in the nail group, additional analysis may be required; 2 ) since the 2 patients were relatively older (80 and 83 years) and had lower BMD (-3.2 and -3.6) than the other patients, reduction of the fracture site might not be maintained well. We thought that our $\gamma$ angle result could recommend that surgeons should consider rotational stability with non-locking Polarus nail.

Radiological examinations revealed that the plate group without medial support showed poor retention of fracture reduction, when compared with the other groups. Although the plate system had only one calcar screw, we found that clinical and radiologic outcomes of the plate group were not inferior to those of the nail group. We thought that a single calcar screw might be sufficient since the medial cortex might not be broad due to spherical shape of the humeral head. Further biomechanical studies are required to confirm how many calcar screws should be positioned for firm medial support.

Our overall results showed no significant difference in the clinical results of surgical treatment of the proximal humerus fracture, either using the plate or nail. However, in the nail group, the rate of failure to maintain reduction during the 1-year follow-up period was significantly higher than in the plate group. Comparing the plate group with or without the medial support gave similar results to previous reports ${ }^{20,28-30)}$; the presence of medial support was found to be beneficial in maintaining the fracture reduction and bone union rate.

This study requires some interpretation due to some limitations. First, in patients with proximal humerus fractures, we performed a retrospective analysis of the results without any randomization in choosing the surgical procedure. The selection bias may have affected the outcome of the operation, because it involves the selection of a plate or nail that is more appropriate for the patient. In order to solve this problem, a prospective study with additional randomization is necessary. Second, the number of nail groups is relatively small compared to the plate, which makes it difficult to conduct a more detailed analysis. If the total number of patients in the nail group is increased, additional analysis would be required. We further attempted to compare the plate and nail groups with subgroups according to the type of fracture. However, a comparative analysis was not performed, due to the small number of patients of each group in type IV (Neer classification). In order to solve this problem, additional analysis is required if the number of patients in the nail group and the number of patients in the Neer IV of each group increases. Third, the follow-up periods were different for 
each patient. In order to analyze the results at the same time, only the data up to 1 year after surgery were analyzed. Although complications during the 1-year period have been analyzed in all cases, complications that are relatively long-term, such as humeral head necrosis, may not have been included in the results. A re-analysis is therefore required after long-term follow-up. The advantage of this study is that the patients were classified and selected based on the same criteria by a single surgeon, who performed surgery using the same instruments under the same environment, and analyzed the results with a relatively high reliability.

\section{Conclusion}

In the treatment of proximal humerus fracture, there was no significant difference in clinical results between periarticular proximal humerus locking plate and Polarus nail. However, in the plate 2 group and nail group, the rate of failure to maintain reduction during the 1-year period after surgery was statistically significantly higher than in the plate 1 group. Unsatisfactory $\gamma$ angle after 1-year data suggests that surgeons should make more effort to adjust the medial support during plate surgery, and the rotational stability during the non-locking nail surgery.

\section{References}

1. Baron JA, Karagas M, Barrett J, et al. Basic epidemiology of fractures of the upper and lower limb among Americans over 65 years of age. Epidemiology. 1996;7(6):612-8.

2. Kannus $P$, Palvanen $M$, Niemi S, Parkkari J, Järvinen $M$, Vuori I. Osteoporotic fractures of the proximal humerus in elderly Finnish persons: sharp increase in 1970-1998 and alarming projections for the new millennium. Acta Orthop Scand. 2000;71(5):465-70.

3. Liew AS, Johnson JA, Patterson SD, King GJ, Chess DG. Effect of screw placement on fixation in the humeral head. J Shoulder Elbow Surg. 2000;9(5):423-6.

4. Neer CS. Displaced proximal humeral fractures. Part I. Classification and evaluation. By Charles S. Neer, I, 1970. Clin Orthop Relat Res. 1987;(223):3-10.

5. Lill H, Hepp P, Korner J, et al. Proximal humeral fractures: how stiff should an implant be? A comparative mechanical study with new implants in human specimens. Arch Orthop Trauma Surg. 2003;123(2-3):74-81.

6. Fankhauser F, Boldin C, Schippinger G, Haunschmid C, Szyszkowitz R. A new locking plate for unstable fractures of the proximal humerus. Clin Orthop Relat Res. 2005;(430):17681.

7. Seide K, Triebe J, Faschingbauer M, et al. Locked vs. unlocked plate osteosynthesis of the proximal humerus: a biomechanical study. Clin Biomech (Bristol, Avon). 2007;22(2):176-82.
8. Hinds RM, Garner MR, Tran WH, Lazaro LE, Dines JS, Lorich DG. Geriatric proximal humeral fracture patients show similar clinical outcomes to non-geriatric patients after osteosynthesis with endosteal fibular strut allograft augmentation. J Shoulder Elbow Surg. 2015;24(6):889-96.

9. Jones CB, Sietsema DL, Williams DK. Locked plating of proximal humeral fractures: is function affected by age, time, and fracture patterns? Clin Orthop Relat Res. 2011;469(12):330716.

10. Adedapo AO, Ikpeme JO. The results of internal fixation of three- and four-part proximal humeral fractures with the Polarus nail. Injury. 2001;32(2):115-21.

11. Agel J, Jones CB, Sanzone AG, Camuso M, Henley MB. Treatment of proximal humeral fractures with Polarus nail fixation. J Shoulder Elbow Surg. 2004;13(2):191-5.

12. Kitson J, Booth G, Day R. A biomechanical comparison of locking plate and locking nail implants used for fractures of the proximal humerus. J Shoulder Elbow Surg. 2007;16(3):362-6.

13. Mølster A, Gjerdet NR, Strand RM, Hole RM, Hove LM. Intramedullary nailing in humeral shaft fractures. Mechanical behavior in vitro after osteosynthesis with three different intramedullary nails. Arch Orthop Trauma Surg. 2001;121(10):5546.

14. Yoon RS, Dziadosz D, Porter DA, Frank MA, Smith WR, Liporace FA. A comprehensive update on current fixation options for two-part proximal humerus fractures: a biomechanical investigation. Injury. 2014;45(3):510-4.

15. Boudard G, Pomares G, Milin L, et al. Locking plate fixation versus antegrade nailing of 3- and 4-part proximal humerus fractures in patients without osteoporosis. Comparative retrospective study of 63 cases. Orthop Traumatol Surg Res. 2014;100(8):917-24.

16. Gradl G, Dietze A, Kääb M, Hopfenmüller W, Mittlmeier T. Is locking nailing of humeral head fractures superior to locking plate fixation? Clin Orthop Relat Res. 2009;467(11):2986-93.

17. Konrad G, Audigé L, Lambert S, Hertel R, Südkamp NP. Similar outcomes for nail versus plate fixation of three-part proximal humeral fractures. Clin Orthop Relat Res. 2012;470(2):602-9.

18. Krivohlávek M, Lukás R, Taller S, Srám J. Use of angle-stable implants for proximal humeral fractures: prospective study. Acta Chir Orthop Traumatol Cech. 2008;75(3):212-20.

19. Lekic N, Montero NM, Takemoto RC, Davidovitch RI, Egol KA. Treatment of two-part proximal humerus fractures: intramedullary nail compared to locked plating. HSS J. 2012;8(2):8691.

20. Gardner MJ, Weil Y, Barker JU, Kelly BT, Helfet DL, Lorich DG. The importance of medial support in locked plating of proximal humerus fractures. J Orthop Trauma. 2007;21(3):185-91.

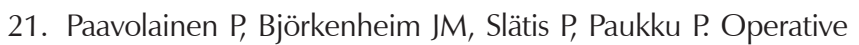
treatment of severe proximal humeral fractures. Acta Orthop Scand. 1983;54(3):374-9. 
22. Poeze M, Lenssen AF, Van Empel JM, Verbruggen JP. Conservative management of proximal humeral fractures: can poor functional outcome be related to standard transscapular radiographic evaluation? J Shoulder Elbow Surg. 2010;19(2):27381.

23. Bahrs C, Rolauffs B, Dietz K, Eingartner C, Weise K. Clinical and radiological evaluation of minimally displaced proximal humeral fractures. Arch Orthop Trauma Surg. 2010;130(5):673-9.

24. Duparc F, Huten D. Conservative treatment of fractures of the upper end of the humerus. Rev Chir Orthop Reparatrice Appar Mot. 1998;84 Suppl 1:121-89.

25. Lescheid J, Zdero R, Shah S, Kuzyk PR, Schemitsch EH. The biomechanics of locked plating for repairing proximal humerus fractures with or without medial cortical support. J Trauma. 2010;69(5):1235-42.

26. Thanasas C, Kontakis G, Angoules A, Limb D, Giannoudis P.
Treatment of proximal humerus fractures with locking plates: a systematic review. J Shoulder Elbow Surg. 2009;18(6):837-44.

27. Hessmann MH, Hansen WS, Krummenauer F, Pol TF, Rommens P. Locked plate fixation and intramedullary nailing for proximal humerus fractures: a biomechanical evaluation. J Trauma. 2005;58(6):1194-201.

28. Charalambous CP, Siddique I, Valluripalli K, et al. Proximal humeral internal locking system (PHILOS) for the treatment of proximal humeral fractures. Arch Orthop Trauma Surg. 2007;127(3):205-10.

29. Lin J. Effectiveness of locked nailing for displaced three-part proximal humeral fractures. J Trauma. 2006;61(2):363-74.

30. Zhang L, Zheng J, Wang W, et al. The clinical benefit of medial support screws in locking plating of proximal humerus fractures: a prospective randomized study. Int Orthop. 2011; 35(11):1655-61. 